\title{
Effects of School Bullying Prevention Camp on the Adolescent Perpetrators of School Violence
}

\author{
Je Jung Lee ${ }^{1}$, Jong Hyun $\mathrm{Kim}^{1}$, and Bung-Nyun $\mathrm{Kim}^{2,3}$ \\ ${ }^{1}$ Department of Psychiatry, Gongju National Hospital, Gongju, Korea \\ ${ }^{2}$ Department of Psychiatry, Seoul National University Hospital, Seoul, Korea \\ ${ }^{3}$ Department of Psychiatry, College of Medicine, Seoul National University, Seoul, Korea
}

Objectives: The purpose of this study was to evaluate the effects of a school bullying prevention camp for adolescent perpetrators of school violence.

Methods: A total of 95 adolescents (boys=73, girls=22) were included in this study. The changes after the program were evaluated using several self-rating scales for the assessment of the degree of depression, loneliness, impulsivity, self-esteem, and interpersonal reactivity compared with the baseline scales.

Results: The school bullying prevention camp significantly reduced the degree of depression severity $(\mathrm{z}=-5.874, \mathrm{p}<0.001)$ and impulsivity scale $(\mathrm{z}=-3.861, \mathrm{p}<0.001)$, while increasing self-esteem $(\mathrm{z}=-2.091, \mathrm{p}=0.037)$. The degree of depression severity $(\mathrm{z}=-4.635, \mathrm{p}<0.001)$, loneliness $(\mathrm{z}=-2.168, \mathrm{p}=0.030)$, and impulsivity $(\mathrm{z}=-2.987, \mathrm{p}=0.003)$ significantly reduced, whereas self-esteem significantly increased $(\mathrm{z}=-2.221, \mathrm{p}=0.026)$ for male students who had no history of child abuse. However, there were no significant changes after the program for the degree of depression, loneliness, impulsivity, self-esteem, and interpersonal reactivity among female students with a history of child abuse.

Conclusion: The results of our study suggest that the development of diverse standardized guidance programs is necessary for teenagers with different characteristics and backgrounds. Such programs are expected to be more effective in preventing school violence.

Key Words: School bullying prevention camp program; Depression; Impulsivity; Self esteem; Empathy; Bullying; Adolescents; Child abuse.

Received: November 12, 2020 / Revision: December 8, 2020 / Accepted: December 9, 2020

Address for correspondence: Je Jung Lee, Department of Psychiatry, Gongju National Hospital, 623-21 Gobunti-ro, Gongju 32601, Korea

Tel: +82-41-850-5700, Fax: +82-41-855-6969, E-mail: selfobjc@naver.com

\section{INTRODUCTION}

Approximately $40 \%$ of middle school students in South Korea have been involved in school violence or bullying [1]. In $2008,10.2 \%$ of 2926 students aged $11-16$ years in South Korea were reported to have experienced bullying from their peers [2]. Persistent school violence may damage the victim's adaptive functions and leave serious mental scars, as well as lead to various other issues, such as behavioral problems, substance abuse, and legal complications for the adolescent perpetrators.

The Act on the Prevention of and Countermeasures against Violence in Schools in South Korea was enacted in 2004. However, the law focuses on protection and treatment of the victims while focusing on social and legal regulations for the perpetrators, but fails to address the perpetrators' mental

This is an Open Access article distributed under the terms of the Creative Commons Attribution Non-Commercial License (https://creativecommons.org/licenses/by-nc/4.0) which permits unrestricted non-commercial use, distribution, and reproduction in any medium, provided the original work is properly cited. vulnerability related to behavioral problems, thus limiting the fundamental prevention of repeated school violence [3]. Thus, the Act on the Prevention of and Countermeasures against Violence in Schools was amended in 2012, which introduced a therapeutic perspective for the perpetrators [3]. In 2013, the Korean Neuropsychiatric Association and National Police Agency jointly developed a school bullying prevention program (the Standard Guidance Program). The program is currently being run in hospitals and clinics nationwide $[4,5]$.

The Standard Guidance Program is an 8-session cognitive behavioral therapy-based school bullying prevention program that was developed for the purpose of improving the capability in impulsivity, emotional control, and empathy of school violence perpetrators [5]. The program is run by psychiatrists or psychologists, who perform baseline and postintervention psychiatric assessments, supervise the overall program, and advise on future intervention for the participants. The effectiveness of the program has been verified 
previously $[4,5]$.

Physical activity reduces depression and anxiety and increases self-esteem in adolescents [6,7]. Meditation-based camp programs can reduce depression and anxiety, increase self-esteem and positive emotions, and decrease negative emotions [8]. Although a clustered randomized controlled trial evaluation on the effectiveness of the program presumably failed to find meaningful outcome, the 'Boost Camp', a two-day school-based transdiagnostic prevention program in Belgium, reportedly had the effect on short-term emotional control [9].

As the Chungnam region in South Korea has a low population density, and it is difficult for the school police to bring school violence perpetrators to a psychiatrist, the Gongju National Hospital implemented a two-day school bullying prevention camp based on the Standard Guidance Program for perpetrators called the Standard Guidance School with cooperation from the Chungnam Provincial Police Agency. In this study, we aimed to examine the sociodemographic characteristics and diagnosis of students who participated in the Standard Guidance School from 2017 to 2019 and evaluate their changes after treatment to determine the effectiveness of the Standard Guidance School. We also examined the factors related to treatment, ultimately to present foundational data for developing various programs tailored to school violence perpetrators.

\section{METHOD}

\section{Participants and procedure}

Among school violence adolescent perpetrators identified by the Chungcheong Provincial Police Agency from 2017 to 2019, 97 first-time offenders involved in minor incidents with a high potential for change through guidance, as indicated by the school police officers, consented to participate in the study. After excluding two students who were only victims of school violence, data from 95 participants were analyzed.

With a consent from the developer [5] of the Standard Guidance Program, the Standard Guidance School was run 5-6 times annually from 2017 to 2019, and a meeting and mental health training were held for the Chungnam and Sejong school police officers in the beginning of the year. This program is an 8-session cognitive behavioral therapy program with 4-8 participants per program and 60 minutes per session (Supplementary Table 1 in the online-only Data Supplement) [4]. In the past, the program was run once a week (2 sessions for visit) for 4 weeks, but our Standard Guidance School was run as a 2-day, 1-night camp program during which all 8 sessions were run by a psychologist, with 'physical activities for improving relationships' and 'breathing relaxation pro- gram' added. Additionally, 2 or 3 school police officers in each region participated in 'a talk with a mentor' with our team and stayed with the adolescents in their rooms (Supplementary Table 2 in the online-only Data Supplement). A psychiatrist first interviewed the students and provided overall advice on the program, including the approach to be taken for each adolescent, during our team meeting and upon completion of the program. The psychiatrist and our team provided advice to the school police officers in the respective regions based on the results of the interview and program. The timetable for the program is shown in Supplementary Table 3 (in the online-only Data Supplement).

\section{Data collection and instruments}

This study was approved by the Institutional Review Board of the Gongju National Hospital in 2020 (2020-07). The study was conducted with reference to the final report for the Standard Guidance Schools conducted from 2017 to 2019 [10-12]. The report cards sent to each student included the questionnaire coding data before and after the program and a report from a psychiatrist on each student (history of child abuse, living with parents, socioeconomic status, history of school violence perpetration/victimization, provisional diagnosis, and future intervention plans). The following questionnaires were used for the baseline and post-program assessments.

The Children's Depression Inventory (CDI) is a modified version of the Beck's Depression Inventory for use in children and adolescents, and this scale was developed by Kovacs [13] and adapted into Korean by Cho and Lee [14]. The scale consists of 27 items, with each item rated on a 3-point scale from 0 to 2 , with a higher score indicating a higher level of depression.

The UCLA Loneliness Scale was developed by Russell et al. [15] and adapted by Kim and Kim [16]. The scale consists of 20 items, with each item rated on a 4-point scale from 1 to 4, with a higher score indicating lower loneliness.

The Barratt Impulsiveness Scale (BIS) was developed by Barratt [17] and adapted by Lee [18]. The scale consists of 23 items rated on a 4-point scale, with a higher score indicating greater impulsiveness.

The Self-Esteem Scale (SES) was developed by Rosenberg [19] and adapted by Jeon [20]. The scale consists of 10 items rated on a 4-point scale from 1 to 4 , with a higher score indicating greater self-esteem.

The Interpersonal Reactivity Index (IRI) was developed by Davis [21] and adapted by Park [22]. The scale consists of 28 items rated on a 5-point scale from 0 to 4 , with a higher score indicating greater empathy. 


\section{Statistical analysis}

The distribution of participants' demographic data and suspected diagnosis were analyzed using descriptive statistics. Differences in provisional diagnoses and history of child abuse according to sex were analyzed using chi-square tests. Changes in depression, loneliness, impulsiveness, self-esteem, and empathy after the program were analyzed using Wilcoxon's signed rank test, and post-program changes were analyzed specifically for sex, age, and child abuse subgroups. All statistical analyses were performed using IBM SPSS statistics version 24.0 (IBM Corp., Armonk, NY, USA), and statistical significance was set at $\mathrm{p}<0.05$.

\section{RESULTS}

\section{Participants' characteristics}

Of the 95 participants, 73 were boys $(76.8 \%)$ and 22 were girls (23.2\%). The mean age was $15.7 \pm 1.19$ years (range, $13-$ 18 years). The female group (16.23 years) was significantly older than the male group (15.60 years). Socioeconomic status was predominantly low $(\mathrm{n}=50,52.6 \%)$ and middle $(\mathrm{n}=42$, $44.2 \%)$. The reason for referral was primarily violence $(\mathrm{n}=70$, $73.7 \%$ ), specifically, 14 students with school violence problems, 5 students with school rule violations, and 6 students with both violence and theft. Forty-six (48.4\%) participants lived with both biological parents, while the remaining participants lived with their grandparents, single parent, stepparents, or lived in an orphanage. Seventy-two (75.8\%) had only been the perpetrators of school violence, while 17 (17.9\%) were both perpetrators and victims of school violence. After the program, 26 (27.4\%) were recommended to undergo counseling, and 27 (28.4\%) were recommended to undergo psychiatric evaluation. Thirty-five participants (36.8\%) were recommended to undergo psychiatric treatment (Table 1).

\section{Distribution of provisional diagnosis by sex}

The provisional diagnoses were attention-deficit/hyperactivity disorder (ADHD, $\mathrm{n}=22,23.2 \%$ ), depressive disorder $(\mathrm{n}=19,20.0 \%)$, conduct disorder $(\mathrm{CD}, \mathrm{n}=10,10.5 \%)$, oppositional defiant disorder (ODD, $\mathrm{n}=5,5.3 \%$ ), adjustment disor$\operatorname{der}(n=5,5.3 \%)$, posttraumatic stress disorder (PTSD, $n=4$, $4.2 \%)$, social anxiety disorder $(n=3,3.2 \%)$, internet gaming disorder (IG, $\mathrm{n}=1,1.1 \%$ ), and social communication disor$\operatorname{der}(\mathrm{n}=1,1.1 \%)$. Twenty-four patients $(25.3 \%)$ were not diagnosed. Thirty-three participants (34.7\%) met the criteria for 2 or more diagnoses.

The participants were divided into externalizing group (ADHD, CD, ODD, etc.), internalizing group (depressive disorder, anxiety disorder, PTSD, etc.), and mixed group (both externalizing and internalizing) and were compared based
Table 1. Descriptive characteristics of sample

\begin{tabular}{|c|c|}
\hline Classification & Values \\
\hline \multicolumn{2}{|l|}{ Sex } \\
\hline Male & $73(76.8)$ \\
\hline Female & $22(23.2)$ \\
\hline \multicolumn{2}{|l|}{ Participation year } \\
\hline 2017 & $30(31.6)$ \\
\hline 2018 & $39(41.1)$ \\
\hline 2019 & $26(27.4)$ \\
\hline \multicolumn{2}{|l|}{ Reasons for request } \\
\hline Violence & $70(73.7)$ \\
\hline Only bullying & $14(14.7)$ \\
\hline Violation of school rule & $5(5.3)$ \\
\hline Stealing and violence & $6(6.3)$ \\
\hline \multicolumn{2}{|l|}{ Living with } \\
\hline Both parents & $46(48.4)$ \\
\hline Grandparents & $9(9.5)$ \\
\hline Single parent & $29(32.5)$ \\
\hline Other & $11(11.6)$ \\
\hline \multicolumn{2}{|l|}{ Self-Esteem Scale } \\
\hline Upper & $3(3.2)$ \\
\hline Middle & $42(44.2)$ \\
\hline Lower & $50(52.6)$ \\
\hline \multicolumn{2}{|l|}{ Child abuse history } \\
\hline No & $59(62.1)$ \\
\hline Yes & $36(37.9)$ \\
\hline \multicolumn{2}{|l|}{ Bullying history } \\
\hline None & $6(6.3)$ \\
\hline Bully & $72(75.8)$ \\
\hline Bully-victim & $17(17.9)$ \\
\hline \multicolumn{2}{|l|}{ Recommend } \\
\hline Information et al. & $7(7.4)$ \\
\hline Counselling & $26(27.4)$ \\
\hline Evaluation & $27(28.4)$ \\
\hline Evaluation and treatment & $35(36.8)$ \\
\hline
\end{tabular}

on sex (Table 2). There were more male students with an externalizing group and more female students with an internalizing group, and the differences were statistically significant (odds ratio $=22.318, \mathrm{p}<0.001$ ).

\section{Changes after the program}

Compared to the baseline, the participants showed significant reductions in the depression score $(\mathrm{Z}=-5.874, \mathrm{p}<0.001)$ and impulsiveness score $(Z=-3.861, p<0.001)$, and a significant increase in the self-esteem score $(\mathrm{Z}=-2.091, \mathrm{p}=0.037)$ after the program. On the other hand, there were no significant changes in loneliness and empathy scores (Table 3). Additionally, the participants with an empathy score of 60 or lower were further analyzed, and these participants did not show 
Table 2. Provisional diagnostic distribution

\begin{tabular}{lccc}
\hline & $\begin{array}{c}\text { Male } \\
(\mathrm{n}=73)\end{array}$ & $\begin{array}{c}\text { Female } \\
(\mathrm{n}=22)\end{array}$ & $\begin{array}{c}\text { Total } \\
(\mathrm{n}=95)\end{array}$ \\
\hline None & $21(28.8)$ & $3(13.6)$ & $24(25.3)$ \\
Externalizing & $32(43.8)^{*}$ & $1(4.55)$ & $33(34.7)$ \\
Internalizing & $11(15.1)$ & $12(54.6)^{*}$ & $23(24.2)$ \\
Mixed & $9(12.3)$ & $6(27.3)$ & $15(15.8)$
\end{tabular}

Data are presented as $n(\%)$. Externalizing: attention-deficit/hyperactivity disorder, conduct disorder, oppositional defiant disorder, etc.; internalizing: depression, anxiety disorder, posttraumatic stress disorder, etc.; mixed: internalizing and externalizing disorder. ${ }^{*} \mathrm{p}<0.001$ a significant change in their empathy scores.

\section{Changes after the program by sex and history of child abuse}

A total of $37.9 \%$ of the participants reported a childhood abuse experience, and the rate of childhood abuse experience was 5.466 times higher among female participants than male participants (odds ratio $=5.466, \mathrm{p}=0.019$ ). Thus, we compared the changes after the program based on sex and history of childhood abuse, as shown in Table 4 . The results showed that male participants without childhood abuse experience

Table 3. Comparison of depression, loneliness, impulsivity, self-esteem, and interpersonal reactivity scales between pre and post school bullying prevention camp in subjects

\begin{tabular}{|c|c|c|c|c|}
\hline & Preprogram & Postprogram & Z & Wilcoxon signed rank test probability \\
\hline Children's Depression Inventory & $11.57(9.52)$ & $6.89(8.64)$ & -5.874 & $<0.001^{*}$ \\
\hline UCLA Loneliness Scale & $36.79(9.26)$ & $35.53(10.27)$ & -1.721 & 0.085 \\
\hline Barratt Impulsiveness Scale & $71.23(9.95)$ & $68.35(10.08)$ & -3.861 & $<0.001^{*}$ \\
\hline Self-Esteem Scale & $28.87(4.79)$ & $29.78(5.18)$ & -2.091 & $0.037^{\dagger}$ \\
\hline Interpersonal Reactivity Index & $53.34(10.67)$ & $54.47(12.68)$ & -1.207 & 0.227 \\
\hline
\end{tabular}

Data are presented as mean (standard deviation). ${ }^{*} p<0.01,{ }^{\dagger} p<0.05$

Table 4. Changes in scales after the school bullying prevention camp in each grouped according to sex and child abuse history

\begin{tabular}{|c|c|c|c|c|}
\hline & Preprogram & Postprogram & Z & $\begin{array}{l}\text { Wilcoxon signed } \\
\text { rank test probability }\end{array}$ \\
\hline \multicolumn{5}{|c|}{ Male with no child abuse history $(n=50)$} \\
\hline CDI & $9.98(7.66)$ & $4.78(5.30)$ & -4.635 & $<0.001^{*}$ \\
\hline UCLA & $36.44(9.13)$ & $33.74(9.92)$ & -2.168 & $0.030^{\dagger}$ \\
\hline BIS & $70.92(9.56)$ & $67.28(9.18)$ & -2.987 & $0.003^{*}$ \\
\hline SES & $29.68(4.84)$ & $31.20(4.76)$ & -2.221 & $0.026^{\dagger}$ \\
\hline$|R|$ & $53.14(10.87)$ & $53.76(11.35)$ & -0.729 & 0.466 \\
\hline \multicolumn{5}{|c|}{ Male with child abuse history $(n=23)$} \\
\hline CDI & $11.30(10.43)$ & $5.70(7.12)$ & -3.221 & $0.001^{*}$ \\
\hline UCLA & $35.87(8.88)$ & $34.78(10.38)$ & -1.294 & 0.196 \\
\hline BIS & $69.65(9.41)$ & $68.57(9.60)$ & -1.104 & 0.270 \\
\hline SES & $29.00(4.01)$ & $28.48(4.94)$ & -0.941 & 0.347 \\
\hline IRI & $50.04(9.04)$ & $50.91(14.10)$ & -0.052 & 0.908 \\
\hline \multicolumn{5}{|c|}{ Female with no child abuse history $(\mathrm{n}=9$ ) } \\
\hline CDI & $11.67(5.10)$ & $6.33(7.23)$ & -2.371 & $0.018^{\dagger}$ \\
\hline UCLA & $37.44(13.45)$ & $40.44(13.97)$ & -0.912 & 0.362 \\
\hline BIS & $68.67(9.21)$ & $66.11(9.53)$ & -1.560 & 0.119 \\
\hline SES & $28.11(6.15)$ & $28.78(6.74)$ & -0.923 & 0.356 \\
\hline $\mid \mathrm{RI}$ & $57.22(8.64)$ & $61.44(12.29)$ & -1.684 & 0.092 \\
\hline \multicolumn{5}{|c|}{ Female with child abuse history $(n=13)$} \\
\hline CDI & $18.08(14.03)$ & $17.54(14.08)$ & -0.491 & 0.624 \\
\hline UCLA & $39.31(7.57)$ & $40.31(6.32)$ & -0.245 & 0.806 \\
\hline BIS & $77.00(11.70)$ & $73.62(12.06)$ & -0.537 & 0.124 \\
\hline SES & $26.08(4.23)$ & $27.31(4.84)$ & -1.505 & 0.132 \\
\hline$|R|$ & $57.23(12.64)$ & $58.69(13.62)$ & -0.767 & 0.443 \\
\hline
\end{tabular}

Data are presented as mean (standard deviation). ${ }^{*} p<0.01,{ }^{\dagger} p<0.05$. CDI: Children's Depression Inventory, UCLA: UCLA Loneliness Scale, BIS: Barratt Impulsiveness Scale, SES: Self-Esteem Scale, IRI: Interpersonal Reactivity Index 
Table 5. Changes in scales after the school bullying prevention camp in each grouped according to age

\begin{tabular}{|c|c|c|c|c|}
\hline & Preprogram & Postprogram & Z & Wilcoxon signed rank test probability \\
\hline \multicolumn{5}{|c|}{ Age $\leq 16(n=67)$} \\
\hline CDI & $11.42(9.01)$ & $6.66(7.48)$ & -4.926 & $<0.001^{*}$ \\
\hline UCLA & $37.04(9.55)$ & $35.52(10.26)$ & -2.181 & $0.029^{\dagger}$ \\
\hline BIS & $71.76(10.27)$ & $69.12(10.16)$ & -3.053 & $0.002^{*}$ \\
\hline SES & $28.85(4.33)$ & $29.93(5.11)$ & -2.160 & $0.031^{\dagger}$ \\
\hline$|\mathrm{R}|$ & $52.22(10.88)$ & $53.55(13.18)$ & -1.042 & 0.297 \\
\hline \multicolumn{5}{|c|}{ Age $>16(n=28)$} \\
\hline CDI & $11.93(10.81)$ & $7.46(11.09)$ & -3.220 & $0.001^{*}$ \\
\hline UCLA & $36.18(8.67)$ & $35.54(10.48)$ & -0.166 & 0.869 \\
\hline BIS & $69.96(9.18)$ & $66.50(9.80)$ & -2.292 & $0.022^{\dagger}$ \\
\hline SES & $28.93(5.84)$ & $29.43(5.41)$ & -0.445 & 0.656 \\
\hline$|\mathrm{R}|$ & $56.00(9.80)$ & $56.68(11.31)$ & -0.573 & 0.567 \\
\hline
\end{tabular}

Data are presented as mean (standard deviation). ${ }^{*} p<0.01,{ }^{\dagger} p<0.05$. CDI: Children's Depression Inventory, UCLA: UCLA Loneliness Sscale, BIS: Barratt Impulsiveness Scale, SES: Self-Esteem Scale, IRI: Interpersonal Reactivity Index

had significant reductions in the depression score $(\mathrm{Z}=-4.635$, $\mathrm{p}<0.001)$, loneliness score $(\mathrm{Z}=-2.168, \mathrm{p}=0.030)$, and impulsiveness score $(\mathrm{Z}=-2.987, \mathrm{p}=0.003)$, and a significant increase in the self-esteem score $(\mathrm{Z}=-2.221, \mathrm{p}=0.026)$, but they did not show significant changes in the empathy score. Male participants with childhood abuse experience showed a significant reduction only in the depression score $(\mathrm{Z}=-3.221, \mathrm{p}=0.001)$, with no significant changes in loneliness, impulsiveness, selfesteem, and empathy scores. Female participants without childhood abuse experience showed a significant reduction only in the depression score $(\mathrm{Z}=-2.371, \mathrm{p}=0.018)$ with no significant changes in loneliness, impulsiveness, self-esteem, and empathy scores. Female participants with childhood abuse experience did not show significant changes in depression, loneliness, impulsiveness, self-esteem, and empathy scores.

\section{Changes after the program by age}

The participants were divided into age groups of $\leq 16$ years and $>16$ years to compare their changes after the program. There were 67 participants in the $\leq 16$ years group, and this group showed significant reductions in the depression $(\mathrm{Z}=$ $-4.926, \mathrm{p}<0.001)$, loneliness $(\mathrm{Z}=-2.181, \mathrm{p}=0.029)$, and impulsiveness scores $(Z=-3.053, p=0.002)$, and a significant increase in the self-esteem score $(Z=-2.160, p=0.031)$, with no significant changes in the empathy score after the program. The $>16$ years group consisted of 28 participants, and they showed significant reductions in the depression $(\mathrm{Z}=-3.220, \mathrm{p}=0.001)$ and impulsiveness scores $(\mathrm{Z}=-2.292, \mathrm{p}=0.022)$, with no significant changes in loneliness, self-esteem, and empathy scores (Table 5).

\section{DISCUSSION}

This study examined the changes in depression, loneli- ness, impulsiveness, self-esteem, and empathy after participation in the Standard Guidance School, a camp-type school violence prevention program for perpetrators, among adolescent school violence perpetrators referred by the school police officers in the Chungnam region of South Korea. A total of $47.4 \%$ of the participants lived with both of their biological parents, which is a markedly lower percentage compared to $87 \%$ reported in a large-scale study [23]. While $57.6 \%$ of the participants in a nationwide Standard Guidance Program administered in 2015 were middle class, $52 \%$ of the paticipants in this study reported their socioeconomic level as 'low.' It can be observed that the subjects of this program were socioeconomically vulnerable. A provisional psychiatric diagnosis was established for $73.2 \%$ of the participants in this study, which is higher than the percentage of $21.5 \%$ reported for the 2015 Standard Guidance Program. A previous study reported that children and adolescents exposed to poverty, child welfare system, and adolescent legal system are at a higher risk for mental health problems [24].

School violence programs are known to be effective when run by experts and when they directly deal with the problem of school violence in a small number of participants $[25,26]$. Additionally, these programs are reported to be effective not only in reducing violent behaviors but also in reducing depression and reinforcing positive emotions, such as self-esteem [26]. Depression is a potent psychological factor that best explains violent and delinquent behaviors in adolescents $[27,28]$. Furthermore, adolescents with low self-esteem are vulnerable to engaging in antisocial behaviors or delinquency because they depreciate themselves and society [29], and to compensate for their self-esteem, they may demonstrate aggressive behaviors toward others [30]. As with the 2015 Standard Guidance Program [4], the present program is also expected to lower participants' involvement in school vio- 
lence perpetration by reducing their depression and increasing self-esteem.

In addition to the reduced depression score and increased self-esteem score observed in the Standard Guidance Program, the present program also significantly reduced the impulsiveness score. The two programs differed in their participant pool, as $16.7 \%$ of the participants of the previous program had an externalizing disorder (ADHD 6.8\%) and an impulsiveness score of 45.64 (before program), 34.0\% of the participants of our program had an externalizing disorder (ADHD 22.7\%) and an impulsiveness score of 70.95 (before program). The difference in participant selection may be attributable to the fact that the school police officers were introduced to and trained about potential clinical groups who could be referred for treatment based on a psychiatric evaluation during an annual meeting with the officers. Moreover, the results are in line with past findings that improvement of impulsiveness, which had been a focus when developing the Standard Guidance Program, was better shown in participants with high baseline impulsiveness [4,31]. Although it was reported that the Standard Guidance Program improved empathy in adolescent school violence perpetrators with low baseline empathy [4], no such changes were observed in this program. In the light of study results showing that empathy can only be improved by implementing various techniques in the long term [32], it is speculated that a short camp for 2 days would have been insufficient to induce changes in empathy.

After participation in this program, male students without childhood abuse experience $(n=50)$ had decreased depression, loneliness, and impulsiveness with improved self-esteem, showing that the program was effective in all aspects with the exception of empathy. Positive childhood experiences serve as a buffer against negative emotions that occur during growth, such as depression and anxiety [33], but adverse childhood experiences, such as child abuse may induce various mental health problems [7] and hinder the improvement of symptoms, such as depression, loneliness, and impulsivity. Moreover, impulsiveness in male students is further related to sensation seeking [34], and physical activities reduce depression and anxiety and increase self-esteem $[6,7]$. In addition to the existing 8-session cognitive behavioral therapy program, some factors might supposedly take meaningful therapeutic roles within our program. Those are: First, camp style program environment in which all participants (adolescents, school police officers, and mental health professionals) stay naturally close together to improve mutual understanding; second, 'relationship-promoting physical activities,' 'abdominal relaxed breathing training,' and 'talking with mentors (polices, mental health professional) are added. But more structural follow-up studies are necessary.
While our program effectively reduced depression in male students with childhood abuse experience and female students without childhood abuse experience, the program was not effective in female students with childhood abuse experience. Students with childhood abuse experience display trauma-related emotions, such as fear, anger, guilt, shame, disgust, sadness, and helplessness, but these symptoms can be improved through dialectical behavior therapy [35]. In the future, our program should additionally implement such a therapeutic approach focused on PTSD for female adolescent perpetrators with childhood abuse experience.

In this study, adolescent participants aged $>16$ years showed decreased depression and impulsiveness. Participants aged 16 years or younger also showed decreased loneliness, depression, and impulsiveness, and had improved self-esteem. This is consistent with previous findings that the Standard Guidance Program is particularly effective for middle school students, who are in turbulent period in terms of emotional and physical development [4], and the present program seems to have been effective in improving loneliness and self-esteem because of the nature of a camp-type program with additional activities for improving relationships.

This study modified the Standard Guidance Program, which was developed as a psychiatric evaluation and cognitive behavioral program for use in Korea, to a camp-type program for use in a non-metropolitan region and investigated its effectiveness. Particularly, this study was significant in that it observed that the camp-type Standard Guidance School was more effective for male students without experience of childhood abuse.

This study has several limitations. First, we did not compare the participants with a control group that did not participate in the program. Second, post-program changes were only analyzed with a self-reported questionnaire. Third, a considerable number of the participants were considered to be potential patients who would benefit from psychiatric treatment, which limits the generalizability of the findings. Fourth, because the duration of the program was only 2 days, we could not observe long-term changes. Fifth, the analyses were performed without controlling for various therapeutic factors. Sixth, the number of female students and students with childhood abuse experience was relatively small, which limits statistical interpretation even with nonparametric statistical methods.

\section{CONCLUSION}

This study analyzed the changes in depression, loneliness, impulsiveness, self-esteem, and empathy after participation in the Standard Guidance School, a camp-type school vio- 
lence prevention program for perpetrators, among adolescent school violence perpetrators referred by school police officers in the Chungnam region of South Korea. After the program, the participants showed reduced depression and impulsiveness with improved self-esteem. One notable finding was that the male students without childhood abuse experience showed reduced depression, loneliness, and impulsiveness and improved self-esteem, while female students with childhood abuse experience showed no significant changes. Furthermore, while high school students showed decreased depression and impulsiveness, middle school students also showed decreased loneliness and improved self-esteem. This study is expected to contribute to modifying the Standard Guidance Program to be tailored to participants of different backgrounds.

\section{Supplementary Materials}

The online-only Data Supplement is available with this article at https://doi.org/10.5765/jkacap.200043.

\section{Acknowledgments}

This study was funded by the Gongju National Hospital in 2020. We extend our gratitude to the Child and Adolescent Mental Health Center at Gongju National Hospital for supporting the program from 2017 to 2019.

\section{Conflicts of Interest}

The authors have no potential conflicts of interest to disclose.

\section{Author Contributions}

Conceptualization: Je Jung Lee, Bung-Nyun Kim. Data curation: Je Jung Lee. Formal analysis: Je Jung Lee. Funding acquisition: Je Jung Lee. Investigation: Je Jung Lee, Jong Hyun Kim. Methodology: Je Jung Lee, Bung-Nyun Kim. Supervision: Je Jung Lee, Bung-Nyun Kim. Visualization: Je Jung Lee, Jong Hyun Kim. Writing_-original draft: Je Jung Lee, Jong Hyun Kim. Writing—review \& editing: all authors.

\section{ORCID iDs}

Je Jung Lee

Jong Hyun Kim

https://orcid.org/0000-0002-0606-2304

Bung-Nyun Kim https://orcid.org/0000-0003-2525-0084 https://orcid.org/0000-0002-2403-3291

\section{REFERENCES}

1) Kim YS, Koh YJ, Leventhal BL. Prevalence of school bullying in Korean middle school students. Arch Pediatr Adolesc Med 2004; 158:737-741.

2) Koo HJ, Kwak KJ, Smith PK. Victimization in Korean schools: the nature, incidence, and distinctive features of Korean bullying or Wang-Ta. J Sch Violence 2008;7:119-139.

3) Lee SH, Jeong JY, Kang TH, Kim MY. A Study on the effectiveness of policies for Aggressor of school violence. Seoul: Korean Institute of Criminology;2014. p.21-24.

4) Kim SA, Kim JI, Choi JW, Lim J, Kim BN. Effects of cognitive behavioral therapy-based program for the adolescent perpetrators of school violence. J Korean Neuropsychiatr Assoc 2017;56:118-126.

5) Sakong JK, Lee YJ, Kim BN, Oh KS, Han SM. The development of national standard program for guiding juvenile delinquents and victims [updated 2015 April 3; cited 2020 Nov 6]. Available from
URL: http://lod.nl.go.kr/resource/CNTS-00067631177.

6) Biddle SJ, Asare M. Physical activity and mental health in children and adolescents: a review of reviews. Br J Sports Med 2011;45:886895.

7) Sadock JB, Sadock AV, Ruiz P. Kaplan \& Sadock's comprehensive textbook of psychiatry. 10th ed. China: Wolters Kluwer;2017.

8) Kim MH. Comparison of the effect of Maum Meditation Program on the depression, anxiety and self-esteem of the children and the juveniles. Jour of KoCon a 2012;12:338-348.

9) Volkaert B, Wante L, Vervoort L, Braet C. 'Boost Camp', a universal school-based transdiagnostic prevention program targeting adolescent emotion regulation; evaluating the effectiveness by a clustered RCT: a protocol paper. BMC Public health 2018;18:904.

10) The Child and Adolescent Mental Health Center. Final report on Standard Guidnace School for bullying perpeturator. Gongju: Gonju National Hospital;2017.

11) The Child and Adolescent Mental Health Center. Final report on Standard Guidnace School for bullying perpeturator. Gongju: Gonju National Hospital;2018.

12) The Child and Adolescent Mental Health Center. Final report on Standard Guidnace School for bullying perpeturator. Gongju: Gonju National Hospital;2019.

13) Kovacs M. The Children's Depression, Inventory (CDI). Psychopharmacol Bull 1985;21:995-998.

14) Cho SC, Lee YS. Development of the Korean form of the Kovacs' Children's Depression Inventory. J Korean Neuropsychiatr Assoc 1990;29:943-956.

15) Russell D, Peplau LA, Ferguson ML. Developing a measure of loneliness. J Pers Assess 1978;42:290-294.

16) Kim KH, Kim JH. Korea UCLA loneliness scale. J Stud Guid 1989; 16:13-30.

17) Barratt ES. Anxiety and impulsiveness related to psychomotor efficiency. Percept Mot Ski 1959;9:191-198.

18) Lee HS. Impulsivity test. Seoul: Korean Guidance;1992.

19) Rosenberg M. Society and the adolescent self-image. Princeton, NJ: Princeton University Press; 1965.

20) Jeon BJ. Self-esteem: a test of its measurability. Yonsei Nonchong 1974;11:107-130.

21) Davis MH. A multidimensional approach to individual differences in empathy. JSAS Catalog of Selected Documents in Psychology 1980;10:85.

22) Park SH. Empathy and prosocial behavior. Seoul: Moonumsa; 1997.

23) Choi IJ, Mo SH, Lee SY, Kim HI. A study on supporting plan for promoting mental health in children and adolescents II. Seoul: National Youth Policy Institute;2012.

24) Stagman S, Cooper JL. Children's mental health: what every policymaker should know. New York, NY: National Center for Children in Poverty, Columbia University;2010.

25) Park-Higgerson HK, Perumean-Chaney SE, Bartolucci AA, Grimley DM, Singh KP. The evaluation of school-based violence prevention programs: a meta-analysis. J Sch Health 2008;78:465-479.

26) Yoon CH, Park SG, Shin IS. A meta-analysis of the effects of school violence prevention programs in Korea. Asian J Educ 2014;15:189215 .

27) Kwak KJ, Mun EY. The relationships of psychological characteristics and depression and antisocial behavior in early adolescence. The Korean Journal of Developmental Psychology 1993;6:29-44.

28) Kim CS. The effect of depression, stress coping, and hardiness on delinquency in adolecsents. The Korean Journal of Health Psychology 2007;12:587-598.

29) Kim JH. The study of art therapy for the prevention of school bullying: focused on aggression and self-esteem of assailant [dissertation]. Seoul: Korea University;2014.

30) Donnellan MB, Trzesniewski KH, Robins RW, Moffitt TE, Caspi A. Low self-esteem is related to aggression, antisocial behavior, 
and delinquency. Psychol Sci 2005;16:328-335.

31) Lee JS. The effect of the group program of cognitive-behavioral therapy on the impulsivity and empathy of juvenile delinquents [dissertation]. Daegu: Catholic University of Daegu;2010.

32) Lee KY, Choi JH, Song JY, Jeon JH. The effectiveness of prevention program of recidivism for school violence on juvenile probation. Korean Journal of Probation 2013;13:249-274.

33) Narayan AJ, Rivera LM, Bernstein RE, Harris WW, Liebernan AF. Positive childhood experiences predict less psychopathology and stress in pregnant women with childhood adversity: a pilot study of the benevolent childhood experiences (BCEs) scale. Child Abuse Negl 2018;78:19-30.

34) Cross CP, Copping LT, Campbell A. Sex differences in impulsivity: a meta-analysis. Psychol Bull 2011;137:97-130.

35) Bohus M, Kleindienst N, Hahn C, Müller-Engelmann M, Ludäscher P, Steil R, et al. Dialectical behavior therapy for posttraumatic stress disorder (DBT-PTSD) compared with cognitive processing therapy (CPT) in complex presentations of PTSD in women survivors of childhood abuse: a randomized clinical trial. JAMA 2020;77:12351245. 
Supplementary Table 1. Schedule of the 8-session school bullying prevention camp

\begin{tabular}{|c|c|c|}
\hline Session & Topic & Contents \\
\hline \multirow[t]{3}{*}{1} & Motivating participation and forming rapport & Understand the purpose and necessity of participating in the program \\
\hline & & Set rules for the duration of program participation \\
\hline & & Get to know each other in the program \\
\hline \multirow[t]{2}{*}{2} & Correctly understanding bullying & Correctly understand the concept and scope of bullying \\
\hline & & Understand the outcomes of bullying, its ripple effects, and the possible punishment for bullying in school \\
\hline \multirow[t]{3}{*}{3} & Developing perspective-taking ability & Understand the other person's perspective \\
\hline & Improving empathetic ability & Think from the perspective of the protagonist in the video \\
\hline & & Empathize with a victim's situation and feelings through indirect experience \\
\hline \multirow[t]{2}{*}{4} & Anger management (controlling anger I) & Feeling thermometer: understand the extent of anger \\
\hline & & Discover my anger patterns, find my real feelings behind anger \\
\hline \multirow[t]{2}{*}{5} & Anger management (controlling anger II) & Understand and correct automatic thinking that causes anger \\
\hline & & Learn how to handle negative feelings \\
\hline \multirow[t]{2}{*}{6} & Self-control and problem-solving & Developing a personalized conflict coping and conflict resolution mechanism \\
\hline & & Learn ways to stop and change when negative feelings begin to form \\
\hline \multirow[t]{2}{*}{7} & Communication training & Learn appropriate social skills in peer relations \\
\hline & & Train how to understand the other person and talk to him/her based on empathic understanding \\
\hline \multirow[t]{3}{*}{8} & Positive self-image, finding hope & Discover how I changed through the program \\
\hline & & Share their vision and dreams and in doing so build mutual emotional support \\
\hline & & Consider what efforts are needed to realize my dream \\
\hline
\end{tabular}


Supplementary Table 2. Comparison of programs

\begin{tabular}{lll}
\hline & \multicolumn{1}{c}{ Standard Guidance Program } & Standard Guidance School (current research program) \\
\hline Duration & $4-5$ weeks (once a week) & 1 night 2 day \\
Type & Visit & Camp \\
Place & Program room & Program room, bed room, living room, gym \\
Number of participants & $4-8$ & $6-8$ \\
Number of program staff & $3-5$ & $7-8$ (+ SPO 3-4) \\
Contents of operation & $8-$-session CBT & 8-session CBT \\
& Pre and post self-reports & Pre and post self-reports \\
& Pre and post psychiatric interviews & Pre and post psychiatric interviews \\
& Pre and post operator meeting & Pre and post staff meeting \\
& & Relationship-promoting physical activities
\end{tabular}

SPO: school police officer, CBT: cognitive-behavioral therapy 
Supplementary Table 3 . Schedule of the school bullying prevention camp

\begin{tabular}{|c|c|c|c|c|}
\hline & \multirow{2}{*}{ Time table } & \multicolumn{3}{|c|}{ Activity contents } \\
\hline & & \multicolumn{2}{|c|}{ Participants } & SPO or program staff \\
\hline \multirow{14}{*}{ Day 1} & $\begin{array}{l}09: 30-09: 40 \\
\quad(10 \mathrm{~min})\end{array}$ & \multicolumn{2}{|c|}{ Introduce program hosts and the facility } & \\
\hline & $\begin{array}{l}09: 40-11: 00 \\
(80 \mathrm{~min})\end{array}$ & Perform pre self-report & $\begin{array}{l}\text { Psychiatric interview } \\
\text { (preliminary evaluation) }\end{array}$ & Preliminary meeting (with program staff and SPO) \\
\hline & $\begin{array}{l}11: 00-11: 50 \\
\quad(50 \mathrm{~min})\end{array}$ & \multicolumn{2}{|c|}{$\begin{array}{l}\text { (1) Understanding the purpose of the program and } \\
\text { setting rules }\end{array}$} & \\
\hline & $\begin{array}{l}11: 50-13: 20 \\
(90 \mathrm{~min})\end{array}$ & \multicolumn{2}{|l|}{ Lunch } & Staff meeting (with program staff and psychiatrist) \\
\hline & $\begin{array}{c}13: 20-14: 20 \\
(60 \mathrm{~min})\end{array}$ & \multicolumn{2}{|c|}{ (2) Correctly understanding bullying } & Hospital tour (due to SPO choice) \\
\hline & $\begin{array}{l}14: 20-14: 30 \\
(10 \mathrm{~min})\end{array}$ & \multicolumn{2}{|l|}{ Break } & \\
\hline & $\begin{array}{l}14: 30-15: 30 \\
(60 \mathrm{~min})\end{array}$ & \multicolumn{2}{|c|}{$\begin{array}{l}\text { (3) Developing perspective-taking ability and } \\
\text { improving empathetic ability }\end{array}$} & \\
\hline & $\begin{array}{l}15: 30-15: 40 \\
(10 \mathrm{~min})\end{array}$ & \multicolumn{2}{|c|}{ Change attires and move to the gym } & Participant management (by SPO) \\
\hline & $\begin{array}{l}15: 40-17: 00 \\
(80 \mathrm{~min})\end{array}$ & \multicolumn{2}{|c|}{ Relationship-improving physical activities } & \\
\hline & $\begin{array}{c}\text { 17:00-18:30 } \\
(90 \mathrm{~min})\end{array}$ & \multicolumn{2}{|l|}{ Dinner and rest } & \\
\hline & $\begin{array}{l}18: 30-19: 30 \\
(60 \mathrm{~min})\end{array}$ & \multicolumn{2}{|l|}{ (4) Anger management I } & \\
\hline & $\begin{array}{l}19: 40-20: 40 \\
(60 \mathrm{~min})\end{array}$ & \multicolumn{2}{|c|}{$\begin{array}{l}\text { (5) Self-control and problem-solving } \\
\text { (6) Communication training }\end{array}$} & \\
\hline & $\begin{array}{c}20: 40-22: 00 \\
(80 \mathrm{~min})\end{array}$ & \multicolumn{2}{|c|}{ Talk with mentors: sharing thoughts and feelings } & Participation (with SPO and program staff) \\
\hline & $\begin{array}{l}22: 00-23: 30 \\
\quad(90 \mathrm{~min})\end{array}$ & \multicolumn{2}{|c|}{$\begin{array}{l}\text { Rest and prepare for sleep (additional tests)/ } \\
\text { 23:30 sleep }\end{array}$} & Participant management (by SPO) \\
\hline \multirow{7}{*}{ Day 2} & $\begin{array}{l}\text { 07:00-08:00 } \\
\text { (60 min) }\end{array}$ & \multicolumn{2}{|l|}{ Rise and get ready } & Participant management (by SPO) \\
\hline & $\begin{array}{l}\text { 08:00-09:00 } \\
\text { (60 min) }\end{array}$ & \multicolumn{2}{|l|}{ Breakfast (outdoor walk) } & \\
\hline & $\begin{array}{c}09: 00-10: 00 \\
\quad(60 \mathrm{~min})\end{array}$ & \multicolumn{2}{|c|}{$\begin{array}{l}\text { Abdominal relaxed breathing training } \\
\text { Review of previous sessions } \\
\text { (7) Anger management II: relaxed breathing } \\
\text { program }\end{array}$} & \\
\hline & $\begin{array}{l}\text { 10:00-10:40 } \\
\quad(40 \mathrm{~min})\end{array}$ & \multicolumn{2}{|c|}{ (8) Building positive self-image } & \\
\hline & $\begin{array}{l}10: 40-12: 00 \\
(80 \mathrm{~min})\end{array}$ & Perform Post self-report & $\begin{array}{l}\text { Psychiatric interview } \\
\text { (final evaluation) }\end{array}$ & \\
\hline & $\begin{array}{l}12: 00-13: 00 \\
(60 \mathrm{~min})\end{array}$ & \multicolumn{2}{|l|}{ Lunch } & $\begin{array}{l}\text { Final meeting (psychiatrists and staff discuss } \\
\text { participants with SPO) }\end{array}$ \\
\hline & $\begin{array}{l}13: 00-13: 30 \\
(30 \mathrm{~min})\end{array}$ & \multicolumn{2}{|c|}{ End of program; return home } & \\
\hline
\end{tabular}

SPO: school police officer 